\title{
Avaliação de Necessidades para a Implementação de um Programa de Transição para a Parentalidade ${ }^{1}$
}

\author{
Sheila Giardini Murta ${ }^{2}$ \\ Universidade de Brasilia \\ Andréia Crispim Rodrigues \\ Isabela Oliveira Rosa \\ Silvia Guimarães Paulo \\ Keila Furtado \\ Pontifícia Universidade Católica de Goiás
}

\begin{abstract}
RESUMO - Este artigo descreve uma avaliação de necessidades para um programa de transição para a parentalidade, feita em dois estudos. Participaram do primeiro estudo treze casais, cujo bebê contava entre 18 a 36 meses. Entrevistas revelaram como estressores os cuidados com o bebê, as mudanças nos papéis familiares e a intrusividade da rede de apoio. Um segundo estudo investigou, através de entrevistas, o conhecimento de oito casais, com filhos recém-nascidos, sobre as suas experiências pessoais de apego e práticas educativas parentais, capacidades sensoriais do bebê, estressores e enfrentamento usado. Os resultados apontaram a exposição a práticas educativas parentais coercitivas e apego inseguro como fatores de risco para a relação pais-bebê. São discutidas as implicações para o planejamento de programas preventivos.
\end{abstract}

Palavras-chave: apego; transição para a parentalidade; avaliação de necessidades; intervenção; prevenção.

\section{Needs Assessment for Implementation of a Parenthood Transition Program}

\begin{abstract}
This paper describes a needs assessment for the implementation of a parenthood transition program. Two studies were realized using interviews. Thirteen couples, with babies of 18 to 36 months, participated in the first study. This study revealed the following stressors: taking care of the baby, changes in family roles and intrusiveness of the social support group. In the second study eight couples with a newborn baby participated. In this study diverse topics were addressed: personal attachment experiences, parental educational practices, sensorial capacities of the baby, stressors and coping methods used. The results indicated coercive educational practices and insecure attachment as risk factors in the relation between parents and baby. The implications for the planning of preventive programs are discussed.
\end{abstract}

Keywords: attachment; parenthood transition; needs assessment; intervention; prevention.

De acordo com Piccinini, Gomes, Moreira e Lopes (2004), a experiência da gravidez é vivenciada com muitas ansiedades pela mulher, tais como aquelas dirigidas à criança (ex.: as expectativas relativas à saúde do bebê), ao companheiro (ex.: como lidar com possíveis sentimentos de ciúmes e isolamento) e a si mesma (ex.: como conciliar os papéis profissionais e pessoais após a vinda do filho). Tais circunstâncias parecem ser ainda mais estressoras quando vivenciadas por pais e mães iniciantes, pela novidade da experiência (Johnson, Burrows \& Williamson, 2004; Warren, 2004). Após o nascimento do primeiro bebê, as mães e os pais são exigidos a desenvolver um amplo repertório comportamental para lidar com as demandas impostas pelo novo papel, como aquelas relativas aos cuidados com a criança (amamentação, choro etc.) e à nova rotina de vida do casal, como a redefinição de papéis e a vivência da sexualidade (Albuquerque, 2000). Neste sentido, tornar-se pai e mãe constitui uma das transições normativas de vida mais estressantes, podendo estar associada a crises na

1 Estudo apoiado pelo CNPq (Processo 401473/2007-4).

2 Endereço para correspondência: Universidade de Brasília, Campus Darcy Ribeiro, Departamento de Psicologia Clínica, Instituto de Psicologia, ICC/Sul, Brasília, DF. CEP: 70.910-900.E-mail: giardini@ unb.br interação conjugal (Barbosa, 1998; Levandowski, Piccinini \& Lopes, 2009; Menezes \& Lopes, 2007) e dificuldades nos cuidados com o bebê (Bradt, 1995).

Intervenções preventivas, que visem ao ensino de estratégias de enfrentamento adequadas para o manejo do estresse inerente a esta nova situação, são de grande relevância nesse momento, a fim minimizar as chances de ocorrência de problemas tais como conflitos conjugais e divórcio (Dessen \& Braz, 2005), depressão materna (Schwengber \& Piccinini, 2004) e maus tratos e negligência para com o bebê (Cia, Williams \& Aiello, 2005; Gravena \& Williams, 2004), que muitas vezes encontram-se interligados. Especificamente em relação a esse último tema, sabe-se que as fases iniciais de desenvolvimento consistem em momentos propícios para a realização de ações de prevenção à violência intrafamiliar (Gray \& MacCormick, 2005; MacLeod \& Nelson, 2000; Shute \& Judge, 2005), possivelmente pela promoção de habilidades e competências na criança e em sua família, maximizando os fatores de proteção para um desenvolvimento saudável (Durlak \& Wells, 1997).

Diversos estudos apontam para o apoio do parceiro como um dos preditores da saúde materna no puerpério (Frizzo \& Piccinini, 2005; Schwengber \& Piccinini, 2004; Warren, 
2004). Em vista disso, intervenções voltadas para o microssistema familiar, incluindo todos os cuidadores do bebê e abordando a relação entre os cônjuges e destes para com o bebê, têm sido recomendadas em detrimento de intervenções dirigidas apenas à mãe (Silva \& Dessen, 2005). Isso porque intervenções dirigidas aos cônjuges podem afetar positivamente a satisfação conjugal, o que constitui um fator de proteção para o desenvolvimento da criança, em oposição ao testemunho de violência entre os pais, sabidamente um fator de risco para o seu desenvolvimento (MacLeod \& Nelson, 2000). Adicionalmente, a satisfação conjugal favorece a qualidade dos cuidados com a criança (Dessen \& Braz, 2005; Mosmann, 2007), o que incrementa ainda mais a necessidade de se incluir o casal nesses programas preventivos.

Apesar destas evidências, ainda são mais freqüentes as intervenções dirigidas exclusivamente à mãe, com vistas à identificação e estimulação das competências sensoriais do bebê e do vínculo mãe-filho (Wendland-Carro \& Piccinini, 1995; Wendland-Carro, Piccinini \& Millar, 1999; Jacobson \& Frye, 1991) e ao ensino de habilidades parentais e informações sobre o desenvolvimento do bebê (Cia et al., 2005; Gravena \& Williams, 2004; Peterson, Tremblay, Ewigman \& Popkey, 2002). É provável que a exclusão dos pais em boa parte destes estudos se deva ao maior acesso do pesquisador à mãe do que ao pai, em serviços de saúde, e ao fato de, tradicionalmente, a mãe adotar o papel de cuidadora e o pai adotar o papel de provedor em várias culturas, principalmente nas gerações passadas (Del Priore, 2006). No entanto, em muitas sociedades contemporâneas, o papel do pai vem se modificando, com um engajamento progressivo nos cuidados com o filho (Levandowski \& Piccinini, 2006; Piccinini, Silva, Gonçalves, Lopes \& Tudge, 2004; Staudt, 2007). Tomando-se em consideração o exposto, estudos que busquem desenvolver e avaliar programas de transição para a parentalidade que incluam o casal, ao invés de apenas a mãe, constituem um dos pontos na agenda de pesquisa nesta área.

A elaboração e a implementação de programas de intervenção precoce focados na interação mãe-pai-bebê, bem como outros programas de prevenção a problemas emocionais e comportamentais na infância, supõem uma longa cadeia de ações, envolvendo desde cuidados teóricos até metodológicos. Estes programas preventivos devem (a) estar fundamentados em uma teoria e em evidências empíricas obtidas em estudos afins, (b) iniciar por uma avaliação de necessidades, (c) ter seu processo de execução monitorado e (d) ter seus resultados avaliados ao longo do tempo (Murta, 2007).

O presente artigo se concentra no segundo elemento desta cadeia: a avaliação de necessidades prévia à implementação de um programa de transição para a parentalidade, focado na promoção de competências parentais e redução de estresse para pais e mães primíparos. Avaliar necessidades é, basicamente, identificar déficits e recursos, com vistas ao planejamento de uma intervenção (Kellam \& Horn, 1997; Posavac \& Carey, 2003). As necessidades podem ser identificadas de diversas formas: a) buscando-se dados epidemiológicos disponíveis em órgãos de controle de saúde, chamadas necessidades normativas (ex.: índices de maus tratos a bebês registrados no Conselho Tutelar); b) comparando-se o problema-alvo em diferentes contextos, denominadas necessidades comparativas (ex.: identificar índices de maus tratos a bebês de mães adolescentes versus mães adultas); c) observando diretamente a população-alvo, conhecidas como necessidades expressas (ex.: observar as principais dificuldades manifestadas pelos pais nas consultas pediátricas nos primeiros meses de vida do bebê) e, por fim, d) ouvindo-se o que a população-alvo tem a dizer sobre o que ela julga precisar, nomeadas de necessidades sentidas (ex.: conduzir entrevistas ou grupos focais com pais para a escuta do que eles percebem como necessidades) (Hawe, Degeling \& Hall, 1990).

A avaliação de necessidades gera informações que irão guiar a tomada de decisão sobre em que intervir, como intervir, onde intervir, quem deve ser o 'receptor' da intervenção, quanto tempo deve durar a intervenção e que variáveis podem ser consideradas indicadores de sucesso durante a implementação da intervenção imediatamente após o seu término e meses ou anos depois disso. Desse modo, no presente estudo buscou-se conduzir uma avaliação de necessidades junto a pais e mães primíparos com vistas à elaboração de um programa de intervenção preventivo ajustado às demandas de famílias nesta etapa do ciclo vital. Trata-se da primeira etapa de um estudo maior, denominado Avaliação de um Programa de Promoção de Competências Parentais e Redução de Estresse para Pais e Mães Primíparos. Este relato está organizado em duas partes: (a) o Estudo 1, exploratório e descritivo, conduzido com pais e mães cujo primeiro filho contava com 18 a 36 meses de idade e (b) o Estudo 2, também descritivo, porém feito com pais e mães cujo primeiro filho era mais jovem, contando até três meses de vida.

\section{Estudo 1}

Este estudo teve por objetivo identificar os sentimentos vivenciados por pais e mães após o nascimento do primeiro filho, as dificuldades no ajustamento à vida familiar e as estratégias de enfrentamento usadas para promover a adaptação do casal aos novos papéis familiares.

\section{Método}

\section{Participantes}

Participaram deste estudo 13 casais adultos, cujos primeiros bebês tinham entre 18 a 36 meses de idade e não apresentaram complicações no parto nem na gravidez. Todos os casais residiam na mesma casa, sendo oito de classe média e cinco de classe baixa. O nível de instrução dos participantes variou de ensino médio incompleto a pós-graduação.

\section{Procedimentos e Instrumento}

Os casais foram recrutados por meio de indicações. Foram incluídos casais cujo primeiro filho tinha entre 18 e 
36 meses de idade, voluntários e excluídos os que haviam vivido gravidez de risco. Durante a visita domiciliar, os casais foram entrevistados conjuntamente por meio de um roteiro de entrevista semi-estruturada para pais e mães primíparos, contendo dez questões que versavam sobre os sentimentos e lembranças agradáveis e desagradáveis em relação à gravidez, parto e pós-parto; eventos estressores vividos; estratégias de enfrentamento utilizadas e sugestões para futuros pais. As entrevistas foram gravadas e seu conteúdo analisado e categorizado por meio de análise de conteúdo (Bardin, 1977). Os casais que desejaram e consentiram em participar do estudo assinaram um Termo de Consentimento Livre e Esclarecido. Ao término do estudo, os participantes foram visitados e receberam uma devolução sobre os resultados do estudo, bem como uma cartilha informativa para pais e mães primíparos construída com base em tais resultados (Murta, Rodrigues, Rosa, Paulo \& Furtado, 2008).

\section{Resultados e Discussão}

Foram identificadas as seguintes categorias e subcategorias temáticas: (1) Sentimentos na primeira semana: insegurança, senso de responsabilidade, ansiedade, medo, mistura de espanto e alegria, cansaço, felicidade, encantamento, orgulho, preocupação, apreensão e realização; (2) Principais dificuldades: falta de informação, dor na amamentação, impotência diante das cólicas, cansaço físico, adaptação do filho à casa, palpites em relação a cuidados, relação com o cônjuge na vida afetiva/sexual e conflito de papéis no caso da mulher - esposa/mãe; (3) Estratégias de enfrentamento: contato com a criança, rede de apoio social e busca de informação; (4) Sugestões para novos pais: fazer um planejamento financeiro, estrutural e emocional do casal; buscar informações; ter contato com o bebê; buscar apoio conjugal, da família extensa e de serviços para facilitação de cuidados com o bebê; e manejo das reações afetivas/sexuais da mulher no puerpério.

Os relatos dos casais relativos aos sentimentos vivenciados na primeira semana e as principais dificuldades na adaptação à nova fase de vida revelaram uma variedade de estressores e sentimentos agradáveis e desagradáveis. Os estressores e o enfrentamento foram assim relatados por uma das mães:

"A maturidade do casal é importante, porque eu pensava que não ia mudar nada, mas claro que muda! Esse negócio de quarentena é bobeira... então demora a voltar o desejo, tem que ser devagar, e a gente tem que contar com a habilidade do marido, porque dói, o peito tá cheio de leite..."

Tais estressores, em sua diversidade e intensidade, sugerem ser esse um momento de vulnerabilidade na vida do casal, apontando algumas direções para programas preventivos. Estes devem incluir informação e apoio para lidar com as necessidades do bebê (ex.: como amamentar e aliviar a dor da mãe no ato de amamentar), a readequação de papéis no casamento, da rotina do casal e da sexualidade e as negociações com a rede de apoio social, quando esta se manifesta intrusiva. Por outro lado, a falta de informação é relatada pelos casais como uma das dificuldades vivenciadas, colocando em risco a satisfação e manutenção desta nova família. Logo, informação correta e relevante parece ser de grande valia neste momento de vida.

Os relatos dos participantes sobre as mudanças na esfera afetivo-sexual revelaram níveis intensos de sofrimento, provavelmente decorrente de ser este um tema pouco esclarecido pela cultura, pela família e pelos serviços de saúde. Como colocado por uma mãe: "A maturidade do casal é importante, porque eu pensava que não ia mudar nada, mas claro que muda, esse negócio de quarentena é bobeira, então demora a voltar o desejo, tem que ser devagar, e a gente tem que contar com a habilidade do marido, porque dói, o peito ta cheio de leite...". Fica evidente, portanto, que programas de transição para a parentalidade que pretendam incluir pais e mães devem ser direcionados, para além dos cuidados com o bebê, ao apoio para o casal. Algumas dimensões da conjugalidade possíveis de serem exploradas nesses programas seriam a satisfação conjugal antes da gestação, o estilo de comunicação do casal (Menezes \& Lopes, 2007), suas estratégias de resolução de conflitos e de manejo das finanças (Sotto-Mayor \& Piccinini, 2005), as expectativas em relação ao cônjuge, o tempo gasto conjuntamente, a sexualidade e o tipo de apego com os próprios genitores (Dessen \& Braz, 2005), por afetarem a satisfação e o estresse conjugal e repercutirem na parentalidade.

Os resultados obtidos na categoria estratégias de enfrentamento e sugestões para novos pais confirmam dados de outros estudos (Frizzo \& Piccinini, 2005; Schwengber \& Piccinini, 2004; Warren, 2004), que apontam a busca de apoio social como uma das principais estratégias de enfrentamento ao estresse gerado pelo nascimento do bebê associadas à saúde mental de pais iniciantes. Dentre as fontes de apoio social, o cônjuge, a família extensa e os serviços de saúde são citados como os mais relevantes.

Por outro lado, o apoio social foi também considerado como invasivo e estressor para os pais e mães primíparos. É possível que lidar com muitas visitas e informações diferentes sobre como cuidar do bebê, muitas vezes contraditórias, sobrecarregue o casal, causando uma confusão em relação "a quem obedecer". Porém, a busca de informação confiável foi citada como uma estratégia de enfrentamento utilizada para um melhor entendimento das mudanças experimentadas e das formas de manejo do bebê, particularmente frente a problemas como cólicas e aqueles relativos à amamentação. Isto reafirma a necessidade de intervenções psicoeducativas, conduzidas por equipes interdisciplinares, capazes de esclarecer, aumentar a auto-eficácia e reduzir a ansiedade dos casais frente às mudanças inerentes à transição para a parentalidade. Sugere ainda que os serviços de saúde precisam estar preparados para o oferecimento de informação correta e de forma adequada neste momento de transição.

Além disto, segundo estes casais, o enfrentamento às mudanças deve começar cedo, a partir de um planejamento anterior à gestação, no seu início ou durante o seu curso, acerca dos recursos e meios necessários para os cuidados futuros com o bebê e a nova vida familiar. Logo, uma implicação 
deste dado é que os programas de transição para a parentalidade devem ter início precoce, ainda na gestação. Isto está em acordo com achados de Honig e Morin (2001), que encontraram evidências de maior efetividade de programas de intervenção com início nesse momento, em comparação aqueles iniciados após o nascimento do bebê.

Ter contato com o bebê foi também citado como uma das estratégias de enfrentamento ao estresse no cuidado à criança e sugestão para os novos pais. Logo, o conteúdo destes programas preventivos poderia incluir informações sobre o desenvolvimento do bebê (Moura et al., 2004), como as suas capacidades sensoriais e temperamento, tal como feito por Wendland-Carro, Piccinini e Millar (1999), ao usarem vídeos informativos para trabalhar com as mães logo após o nascimento do bebê, ainda no hospital. Estas informações poderiam favorecer a sensibilidade parental, permitindo aos pais prestar mais atenção ao bebê, interpretar seus sinais e atendê-los adequadamente (Silva, Pendu, Pontes \& Dubois, 2002).

\section{Estudo 2}

O Estudo 2 foi conduzido com o objetivo de identificar os fatores de risco e de proteção entre casais cujo primeiro filho era recém-nascido, de modo a delinear focos para uma intervenção individualizada em contexto de visita domiciliar. Especificamente, o estudo se concentrou em avaliar estressores envolvidos na transição para a parentalidade, estratégias de enfrentamento adaptativas e não adaptativas utilizadas por pais e mães para lidar com os mesmos, o conhecimento do casal sobre as capacidades sensoriais do bebê e o tipo de apego e de práticas educativas parentais vivenciadas na relação com os próprios pais.

\section{Método}

\section{Participantes}

Participaram desse estudo oito casais, com tempo de casamento variando entre um ano e três meses e 10 anos. A idade dos maridos variou entre 22 e 37 anos e a das esposas, entre 21 e 38 anos. O nível de instrução variou entre ensino médio incompleto e pós-graduação. Dos oito casais, três tinham renda mensal entre 350 e 700 reais, três entre 700 e 1500 reais, e dois acima de 1500 reais mensais. As profissões relatadas pelas mulheres foram: do lar (4), assistente administrativo (1), estudante (1), psicóloga (1) e secretária (1), enquanto que as profissões relatadas pelos homens foram: engenheiro (1), cabeleireiro (1), professor (1), estudante (1), protético (1), açougueiro (1), auxiliar de serviços gerais (1) e operador de frotas (1). Todos se encontravam com o primeiro filho, nascido a termo, com até 3 meses de idade. Entre os casais, cinco planejaram a gravidez e dois não planejaram. Todos eles foram localizados através do Departamento de Recursos Humanos de uma universidade do Centro-Oeste do Brasil e via Programa de Saúde da Família, ambos na mesma cidade. Foram excluídas participantes que haviam vivenciado gravidez de risco e que o bebê havia nascido pré-termo.

\section{Procedimentos e Instrumento}

Foram realizadas visitas domiciliares, quando foram conduzidas entrevistas com o casal, conjuntamente, utilizando-se um roteiro estruturado, que buscou informações sobre: a) dados demográficos (oito questões; ex.: Com o que vocês trabalham?); b) riscos psicossociais (15 questões; ex.: Vocês fazem ou já fizeram uso de medicamento controlado?); c) conhecimento sobre capacidades sensoriais do bebê (15 questões; ex.: O que vocês sabem sobre a capacidade do recém-nascido de enxergar?); d) experiência de apego do casal com seus progenitores (nove questões; ex.: Se fosse para você resumir o jeito do seu pai com você quando você era criança, e tivesse que usar cinco palavras para descrever o jeito dele com você, que palavras você usaria? Por que você escolheu estas palavras?); e) experiência de práticas educativas parentais (sete questões; ex.: Seus pais costumavam brincar com vocês? Do que eles brincavam?); f) estressores vivenciados nos últimos 12 meses (checklist com 33 itens; ex.: morte de membro da família) e g) enfrentamento e rede de apoio social (16 questões; ex.: Vocês participam de algum grupo?). Para a realização das entrevistas, foram feitas de duas a três visitas à residência do casal, com data e horários definidos por eles. As entrevistas foram gravadas e seu conteúdo descrito e categorizado, conforme procedimentos de análise de conteúdo propostos por Bardin (1977). Cuidados éticos foram tomados, por meio do esclarecimento dos objetivos do estudo, confidencialidade quanto à identidade dos entrevistados e caráter voluntário da participação. Os casais que desejaram e concordaram em participar do estudo assinaram um Termo de Consentimento Livre e Esclarecido. A devolução de resultados aos participantes seguiu o mesmo procedimento usado no Estudo 1.

\section{Resultados e Discussão}

\section{Riscos Psicossociais}

Todos os casais relataram que seus bebês gozavam de boa saúde e maior parte deles (sete casais) fez o acompanhamento pré-natal regularmente. Seis mulheres tiveram a companhia do esposo nas consultas de pré-natal em, pelo menos, uma vez. Nenhum casal apresentava problemas de saúde ou uso de álcool, drogas, medicamento controlado ou fumo. Cinco casais planejaram a gravidez. Dois não planejaram, porém relataram terem se sentido muito felizes e acolhido bem a notícia. Um casal não planejou, relatando que a gravidez causou, ao início, muito estresse no relacionamento (eram namorados na ocasião) e nas finanças.

\section{Conhecimento sobre Capacidades Sensoriais do Bebê}

Em relação ao conhecimento sobre o desenvolvimento do bebê e suas habilidades sensoriais, todos os casais reconheceram que seus bebês apresentavam a capacidade de enxergar e de sorrir. Quanto à visão, mesmo os que não tinham esse conhecimento antes do nascimento do bebê, a 
partir da interação com os filhos perceberam tais habilidades nos mesmos. Um dos casais afirmou que a percepção obtida na interação com o bebê contrariava uma informação recebida em um serviço de saúde: "Eles costumam dizer que criança não enxerga, né, só que... sinceramente, não é criticando quem estuda não, eu acho que tá errado, porque desde que ela nasceu, não só procura o som, mas ela olha...". Esse dado sugere que a equipe de saúde que ofereceu o atendimento pode não estar devidamente informada acerca das habilidades sensoriais do recém-nascido. Sobre a capacidade de sorrir, um dos participantes afirmou: "Se eu chegar ali e ela tiver chorando e eu falar um 'a', ela escuta minha voz, pára de chorar e começa a rir".

O relativo desconhecimento sobre as capacidades sensoriais do bebê foi bem colocado por Moura e Ribas (2004), ao discutirem as distorções da cultura sobre práticas de cuidados ao bebê, bem como a formação desatualizada de alguns profissionais de saúde, ao divulgarem a informação errônea de que o bebê nasce sem enxergar, capaz apenas de mamar e dormir, e ao recomendarem manter o bebê em ambientes escuros e silenciosos, com maior ênfase na assepsia e nenhuma na estimulação cognitiva, social e psicomotora ao bebê. Este descompasso entre as informações recebidas dos profissionais de saúde e a percepção dos pais foi um achado relevante, que aponta a urgência de mudanças na formação destes profissionais e nos serviços de educação em saúde.

Dos 16 participantes, 15 afirmaram reconhecer as habilidades auditivas ("É ótimo, qualquer barulhinho assusta (o bebê,) ou então a gente falando. É... Desde a barriga"), gustativas ("Qualquer remédio diferente... Faz careta, faz vômito") e táteis (dor, calor e frio) do recém-nascido. A habilidade menos reconhecida foi o olfato ("Minha esposa estava tomando banho e ele chorando, então coloquei o sutiã dela, na cama perto dele... Ele gostou, se acalmou”.), tendo sido relatada por 12 participantes.

Quando questionados sobre as estratégias usadas para acalmar o bebê, os casais relataram fazer uso das seguintes: segurar o bebê no colo, conversar com ele, identificar o choro do bebê, trocá-lo de posição e deixá-lo no berço. Um dos participantes relatou ter "vontade de chorar junto com o bebê", em situações de desconforto intenso do filho.

\section{Experiência de Apego do Casal com seus Progenitores}

A experiência de apego do casal com seus progenitores foi agrupada em duas categorias: apego seguro e apego inseguro (Bowlby, 1969/1990). Relatos de lembranças da relação com os pais, durante a infância, caracterizada por intimidade, proteção/cuidado, afeto e sincronia foram categorizados como apego seguro, como ilustrado a seguir: "Brincava de boneca comigo, sempre foi criança junto comigo, sempre me acompanhou nas fases. É, a gente sentava na areia pra brincar de barrinho, ela sentava com a gente, fazia bolinho, ajudava a enfeitar, ajudava a arrumar os lugares todinhos, pra brincar".

Já relatos de lembranças da relação com os pais durante a infầncia, caracterizadas por frieza/distância, abandono/negligência, ódio/hostilidade, conflito e ausência de lembranças, tal como exemplificado no relato: "Meu pai... era ausente, muito duro, muito frio, não tinha diálogo, a gente tinha que ficar chamando ele, muito distante... indiferente em relação aos filhos, foi um reprodutor e minha mãe dona de casa e pronto", foram categorizados como apego inseguro.

As categorias apego seguro e inseguro foram analisadas separadamente (de tal forma que um mesmo indivíduo poderia apresentar lembranças categorizadas em apego seguro e inseguro) e para cada um dos cônjuges (as experiências de apego foram individuais e foi tomadas como medida de análise o indivíduo e não o casal). A Tabela 1 evidencia que relatos de lembranças de interações com os cuidadores típicas de apego seguro predominaram sobre as de apego inseguro. Quatro participantes relataram lembranças da interação com os cuidadores na infância típicas de apego inseguro.

Tabela 1. Frequência de participantes que relataram lembranças típicas de apego seguro e inseguro com seus cuidadores

\begin{tabular}{lccc}
\hline Tipos de Apego & Pai e Mãe & Pai & Mãe \\
\hline Seguro & 11 & 3 & 1 \\
Inseguro & 1 & 1 & 3 \\
\hline
\end{tabular}

Estes dados parecem relevantes do ponto de vista do planejamento da intervenção, uma vez que, a princípio, os quatro participantes que tiveram experiência de apego inseguro estariam em maior risco de interagir de modo não responsivo com seus filhos do que aqueles que tiveram experiência de apego seguro (Bowlby, 1969/1990), podendo requerer mais horas de intervenção, com estratégias dirigidas para o desenvolvimento da responsividade na relação com o bebê (Wendland-Carro, Piccinini \& Millar, 1999), bem como o levantamento de fatores de proteção presentes na vida do casal, para o fortalecimento do seu potencial de resiliência (Walsh, 2005; Cecconello \& Koller, 2004).

\section{Experiência de Práticas Educativas Parentais}

$\mathrm{Na}$ experiência de práticas educativas parentais vivenciadas pelos casais com seus próprios genitores, foram analisados os aspectos: afetividade, limites, comunicação, exigência de amadurecimento (Baumrind, 1967) e modelo moral (Gomide, 2004). Dentre os dezesseis participantes, quinze descreveram os pais como afetuosos, ocorrendo estas demonstrações de afeto por meio de palavras, preocupação, brincadeiras e cuidado. Mesmo quando as expressões desses sentimentos ou contato físico não eram muito presentes, eles se sentiam amados: “eu sentia que sim 'né', pela preocupação 'né', mesmo com todos os problemas, à maneira deles, eles gostavam sim, essa coisa eu sentia muito bem do meu pai e da minha mãe, sempre senti". Um dos participantes relatou ausência de afetividade dos seus pais.

Todos os 16 participantes relataram que os pais impunham limites, ensinando o que era ou não permitido: "Sim, sempre ensinava o que era permitido e o que não era". Catorze dos 16 entrevistados relataram que, quando os pais queriam corrigir algo errado que eles faziam, primeiro havia uma conversa instruindo sobre o acontecido (controle por regras). Caso essa não solucionasse o problema, ocorria a punição: 
"A primeira fase era a fala, depois de várias falas, quando não solucionava, apanhava". Destes 14 , três relataram que as conversas resolviam e não havia punições físicas, e um dos participantes relatou que, além do controle por regras e punição, outra estratégia usada pelos seus pais foi o reparo por conseqüência: "Lembro, por exemplo, da adolescência que estava chutando bola e quebrei a porta de vidro e tive que trabalhar no jardim dos vizinhos para pagar a porta". Os outros dois participantes disseram que não havia conversa (controle por regras), pois os pais partiam logo para as ameaças e punições: "Não tinha nem uma psicologia, não. Era a lei da vara de amora, fio de ferro, 'né', chinelo!"

$\mathrm{Na}$ categoria comunicação, 14 participantes relataram ter vivenciado experiência de diálogo para orientação, monitoramento e consequente senso de segurança e confiança: "A gente era sempre aberto, muito aberto. Sobre namorado... eles sempre explicavam sobre drogas, sexo, o mundo lá fora.. sempre”. Dois participantes não vivenciaram essa experiência.

Quanto à exigência de amadurecimento, caracterizada pela designação de tarefas para construção de senso de responsabilidade, foi vivenciada com superproteção por um participante, com exigência excessiva por quatro participantes, enquanto que os outros 11 relataram exigência por eles experienciada como adequada: "Sim, ajudar na casa, mas as tarefas escolares em primeiro lugar, né! Meu pai tinha um comércio também e a gente ajudava".

Todos os participantes relataram ter nos pais e/ou mães um modelo moral, com o ensino de valores como honestidade, generosidade, tolerância, sinceridade e outros resultantes das práticas educativas dos pais. Eles relataram pretender transmitir esse modelo para os filhos: "Aprendi muito, até mesmo assim... na educação, na experiência de vida conjugal deles, eu nunca vi meu pai e minha mãe brigando, isso eu quero passar".

Tal como os dados sobre apego, os dados sobre a exposição a práticas educativas parentais de risco indicam os casais em maior vulnerabilidade, incluindo os que tiveram experiência pessoal com limites ausentes ou violentos, comunicação deficitária, superproteção, exigências excessivas, ausência de afetividade e de ensino de valores morais. Uma implicação destes dados para o planejamento de intervenções seria o desenvolvimento de valores morais e de habilidades parentais relativas à comunicação, afetividade, limites e estímulo ao desenvolvimento de responsabilidades adequadas à idade. Deste modo, estaria se reduzindo os riscos da transmissão intergeracional de práticas educativas parentais de risco, negligência e maus tratos para com o bebê (Cecconello, Antoni \& Koller, 2003; Salvo, Silvares \& Toni, 2005; Silva \& Marturano, 2002).

\section{Estressores e Estratégias de Enfrentamento}

Os estressores gerais, não relacionados à parentalidade, vivenciados nos últimos 12 meses, mais freqüentemente relatados foram: aumento de responsabilidades no trabalho, mudança nos horários e condições de trabalho, desemprego do cônjuge, início de um novo trabalho, diminuição de renda e doença na família. Por sua vez, os estressores específicos da parentalidade relatados na entrevista foram: compreender e ajustar-se aos ritmos (ex.: duração do sono) e choro do bebê, dificuldade de alimentação do bebê, cólica do bebê, receber visitas no primeiro mês e insegurança do pai em cuidar do bebê (ex.: segurar). Os estressores gerais e específicos da parentalidade e suas respectivas freqüências estão apresentados na Tabela 2.

As estratégias de enfrentamento foram categorizadas em enfrentamento focado no problema (usadas para resolver ou prevenir o problema) e enfrentamento focado na emoção (usadas para aliviar as emoções desagradáveis decorrentes da situação-problema) (Lazarus \& Folkman, 1984). Em relação às estratégias de enfrentamento focadas no problema, constatou-se que as mais usadas (ver Tabela 3 ) foram busca de informação sobre cuidados com o bebê, dar toda a assistência necessária ao bebê, estabelecer contato físico com o bebê, busca de serviço de saúde (ex.: para vacinação), busca de apoio da família de origem (mãe, irmã etc), conversa com bebê para reasseguramento (ex.: "calma, papai tá aqui") e revezamento entre pai e mãe nos cuidados com o bebê (busca de apoio do cônjuge nos cuidados com bebê). Em relação às estratégias de enfrentamento focadas na emoção, a categoria mais utilizada (ver Tabela 3 ) foi dormir, seguida pela categoria de admiração das reações do bebê.

Os dados indicam que, aos estressores relativos aos cuidados com o bebê, também apontados no Estudo 1, somam-se os estressores relativos ao trabalho, indicando que o desenvolvimento de estratégias de enfrentamento ao estresse poderia ser de grande utilidade para os casais. De acordo com os casais entrevistados neste estudo, a transição para a parentalidade requer uma grande diversidade de estratégias de enfrentamento focadas no problema, seguidas de estratégias de alívio do desgaste vivido. Os dados relativos a formas de enfrentamento confirmam os do Estudo 1, indicando que a própria interação com o bebê e a busca da rede de apoio social, na qual está incluído o(a) cônjuge, estão entre as principais formas de lidar com esta transição de vida. Como os estressores são vários, também o enfrentamento precisa ser enriquecido. Ainda que o presente estudo não permita conclusões de natureza correlacional, a julgar pelos relatos dos casais, pode-se levantar a hipótese de que quanto maior e mais criativo o repertório de enfrentamento do casal (como conversar com casais amigos que também têm filhos pequenos) melhor a sua adaptação a esta etapa do desenvolvimento familiar. Neste sentido, seria desejável o aumento da participação paterna no parto e o engajamento em grupos de orientação à gestante ou casal, neste estudo relatado por apenas um dos casais. Por fim, salienta-se que a diversidade de estratégias de enfrentamento identificadas entre os casais esteja refletindo variáveis sócio-econômicas, como acesso a grupos informativos e a hobbies, como tocar instrumento, que foram estratégias relatadas por um casal de classe média e instrução superior. Tal aspecto também deve ser levado em consideração no planejamento de uma intervenção. Assim, a comparação do repertório de enfrentamento entre famílias com e sem restrições sócio-econômicas, neste estudo vista de modo exploratório, pode ser um objeto de análise para estudos futuros. 
Tabela 2. Frequência de relatos de estressores gerais e específicos da maternidade, por casal

\begin{tabular}{|c|c|c|}
\hline Tipo de Estressor & Categorias & f \\
\hline \multirow{23}{*}{ Estressores gerais } & Aumento de responsabilidades no trabalho & 6 \\
\hline & Mudança nos horários e condições de trabalho & 5 \\
\hline & Desemprego do cônjuge & 5 \\
\hline & Início de um novo trabalho & 3 \\
\hline & Diminuição de renda & 3 \\
\hline & Doença na família & 3 \\
\hline & Aquisição de residência própria & 2 \\
\hline & Mudança de residência de uma cidade para outra & 2 \\
\hline & Casamento & 2 \\
\hline & Noivado & 2 \\
\hline & Dificuldades sexuais & 2 \\
\hline & Morte de amigo próximo & 2 \\
\hline & Problemas com colegas de trabalho & 2 \\
\hline & Mudança para um novo tipo de trabalho & 2 \\
\hline & Doença que exigiu repouso ou afastamento de atividades & 2 \\
\hline & Problemas com chefia no trabalho & 2 \\
\hline & Vencimento de um empréstimo & 1 \\
\hline & Perda de emprego & 1 \\
\hline & Mudança em discussões com o cônjuge & 1 \\
\hline & Adaptação à cultura/crenças da família do cônjuge & 1 \\
\hline & Novo casamento dos pais & 1 \\
\hline & Prisão de um membro próximo da família & 1 \\
\hline & Divórcio dos pais & 1 \\
\hline \multirow{6}{*}{ Estressores específicos da maternidade } & Dificuldades para compreender e ajustar-se aos ritmos do bebê & 5 \\
\hline & Choro do bebê & 5 \\
\hline & Dificuldade de alimentação do bebê & 3 \\
\hline & Cólica do bebê & 2 \\
\hline & Visitas no primeiro mês & 1 \\
\hline & Insegurança em relação à capacidade do pai de cuidar do bebê & 1 \\
\hline
\end{tabular}

\section{Considerações Finais}

Os dados dos Estudos 1 e 2 indicam que os programas de transição para a parentalidade devem focar na relação cuidadores-bebê, na relação conjugal e no manejo da rede de apoio. Especificamente, estes programas devem ensinar aos novos pais estratégias variadas para: lidar com os sentimentos ambivalentes resultantes do nascimento do bebê, interpretar e atender ao choro do bebê e suas diversas necessidades, favorecer a participação do pai nos cuidados com o bebê, encorajar a percepção das capacidades sensoriais do bebê, lidar com mudanças nos papéis e na sexualidade do casal, fortalecer a rede de apoio social e proteger-se da intrusão dessa rede.
Os dados sugerem ainda, como já apontado em outros estudos (Cecconello et al., 2003; Frizzo \& Piccinini, 2005; Salvo et al., 2005; Wendland-Carro et al., 1999) que a exposição a práticas educativas parentais coercitivas e apego inseguro, em alguns casais, pode configurar situações de maior vulnerabilidade. Nesses casos, podem ser necessárias intervenções mais longas e com conteúdo mais voltado para a promoção da capacidade de resiliência, da responsividade na interação com o bebê, da prevenção de maus tratos contra o bebê e o cônjuge e da modificação de crenças sobre práticas educativas parentais.

Os resultados também mostraram que, não somente os pais precisam ser informados sobre as capacidades sensoriais do bebê, mas também os profissionais de saúde que prestam 
Tabela 3. Frequência de relatos de estratégias de enfrentamento utilizadas pelos casais.

\begin{tabular}{|c|c|c|}
\hline Tipo de enfrentamento & Categoria & f \\
\hline \multirow{16}{*}{$\begin{array}{l}\text { Estratégias de enfrentamento } \\
\text { focadas no problema }\end{array}$} & Buscar informação sobre cuidados com o bebê & 8 \\
\hline & Dar a assistência necessária ao bebê & 8 \\
\hline & Estabelecer contato físico com o bebê & 8 \\
\hline & Buscar serviço de saúde & 7 \\
\hline & Buscar apoio da família de origem & 7 \\
\hline & Conversar com bebê para reasseguramento & 7 \\
\hline & Revezar entre pai e mãe nos cuidados com o bebê & 7 \\
\hline & Buscar orientação médica & 6 \\
\hline & Oferecer cuidados ao bebê & 6 \\
\hline & Identificar as causas do choro do bebê & 5 \\
\hline & Conversar com cônjuge para tomada de decisões & 5 \\
\hline & Aceitar as mudanças como parte da vida & 4 \\
\hline & Planejar busca de curso para pais na igreja & 1 \\
\hline & Participar em grupo de mães gestantes & 1 \\
\hline & Pai participar no parto & 1 \\
\hline & Buscar empregada doméstica & 1 \\
\hline \multirow{12}{*}{$\begin{array}{l}\text { Estratégias de enfrentamento } \\
\text { focadas na emoção }\end{array}$} & Dormir & 8 \\
\hline & Admirar das reações do bebê & 7 \\
\hline & Tomar banho demorado & 3 \\
\hline & Comer mais que de costume & 3 \\
\hline & Dialogar com cônjuge & 3 \\
\hline & Deitar & 2 \\
\hline & Partilhar experiência com casais amigos que têm filhos pequenos & 2 \\
\hline & Comer mais devagar & 1 \\
\hline & Ter intimidade física com o cônjuge & 1 \\
\hline & Freqüentar igreja & 1 \\
\hline & Tocar instrumento musical & 1 \\
\hline & Praticar atividades físicas & 1 \\
\hline
\end{tabular}

atendimento às famílias e gestantes precisam ter sua formação atualizada e aprimorada. Pode-se ainda indagar sobre a própria formação dos psicólogos, possíveis professores de médicos e enfermeiros, bem como o conteúdo das disciplinas de Psicologia aplicada aos cursos de saúde. Como estará o ensino de psicologia nos curso de Medicina, Enfermagem e áreas afins? Quão articulado com a prática está este ensino? Quão fundamentado em pesquisas recentes está este ensino? Este é um tema relevante para estudos futuros.

Os dados mostraram ainda, em coerência com achados de estudos afins (Levandowski et al., 2009; Menezes \& Lopes, 2007; Sotto-Mayor \& Piccinini, 2005), que a dimensão da conjugalidade precisa ser cuidada, assim como a dimensão da parentalidade. Seria pertinente que avaliações de necessidade futuras investiguem, além das variáveis aqui discutidas, também o repertório de habilidades sociais do casal e indícios de violência física, psicológica ou sexual na relação conjugal. Em seu conjunto, estes dados podem guiar a construção de materiais educativos, como cartilhas para pais e mães primíparos (Murta et al., 2008), preferencialmente com texto ilustrado e acessível para pessoas com e sem instrução, a ser usado como ferramenta para educação em saúde, seja em intervenções domiciliares ou grupais ou em serviços de atenção à saúde da família gestante. Finalmente, cabe dizer que a qualidade da interação pais-bebê, as práticas educativas parentais, a satisfação conjugal, as habilidades sociais conjugais e a incidência de violência contra a criança e conjugal seriam indicadores úteis para a avaliação de resultados e o impacto destes programas para famílias na transição para a parentalidade.

\section{Referências}

Albuquerque, M. C. S. (2000). O significado da sexualidade para mulheres grávidas. Tese de Doutorado, Universidade de São Paulo, São Paulo.

Barbosa, L. P. (1998). A vivência de crises no ciclo gravídicopuerperal. Dissertação de Mestrado, Universidade Federal do Ceará, Fortaleza. 
Bardin, L. (1977). Análise de conteúdo. Lisboa: Edições 70.

Baumrind, D. (1967). Child care practices anteceding three patterns of preschool behavior. Genetic Psychology Monographs, 75, 43-88.

Bowlby. J. (1990). Apego: a natureza do vínculo (A. Cabral, Trad.). São Paulo: Martins Fontes (Trabalho original publicado em 1969).

Bradt, J. A. (1995). Tornando-se pais e mães: famílias com filhos pequenos. In B. Carter \& M. McGoldrick (Eds.), As mudanças no ciclo de vida familiar. Uma estrutura para a terapia familiar (M. A. V. Veronese, Trad.) (pp. 206-222). Porto Alegre: Artes Médicas (Trabalho originalmente publicado em 1989).

Cecconello, A. M., Antoni, C., \& Koller, S. H. (2003). Práticas educativas, estilos parentais e abuso físico no contexto familiar. Psicologia em Estudos, 8, 45-54.

Cecconello, A. M., \& Koller, S. H. (2004). Inserção ecológica na comunidade: uma proposta metodológica para o estudo de famílias em situação de risco. In S. H. Koller (Ed.), Ecologia do desenvolvimento humano: pesquisa e intervenção (pp. 267292). São Paulo: Casa do Psicólogo.

Cia, F., Williams, L. C. A., \& Aiello, A. L. R. (2005). Intervenção focada na família: um estudo de caso com mãe adolescente e criança de risco. Revista Brasileira de Educação Especial, 11, 49-66.

Del Priore, M. (2006). História das Mulheres no Brasil. São Paulo: Contexto.

Dessen, M. A., \& Braz, M. P. (2005). As relações maritais e suas influências nas relações parentais: implicações para o desenvolvimento da criança. In M. A. Dessen \& A. L. Costa Júnior (Eds.), A ciência do desenvolvimento humano: tendências atuais e perspectivas futuras (pp. 132-151). Porto Alegre: Artmed.

Durlak, J. A., \& Wells, A. M. (1997). Primary prevention mental health programs for children and adolescents: a meta-analytic review. American Journal of Community Psychology, 25, 115-142.

Frizzo, G. B., \& Piccinini, C. A. (2005). Interação mãe-bebê em contexto de depressão materna: aspectos teóricos e empíricos. Psicologia em Estudo, 10, 47-55.

Gomide, P. I. C. (2004). Pais presentes, pais ausentes. Petrópolis: Vozes.

Gravena, A. C., \& Williams, L. C. A. (2004). Intervenção com gestantes adolescentes de baixo poder aquisitivo: prevenção de maus tratos e negligência. Temas sobre Desenvolvimento, 13, 14-20.

Gray, R., \& McCormick, M. C. (2005). Early childhood intervention programs in the US: recent advances and future recommendations. The Journal of Primary Prevention, 26, 259-275.

Hawe, P., Degeling, D., \& Hall, J. (1990). Evaluating health promotion. A guide to health workers guide. Sydney: Maclennan \& Petty.

Honig, A. S., \& Morin, C. (2001). When should programs for teen parents and babies begin? Longitudinal evaluation of a teen parents and babies program. The Journal of Primary Prevention, 21, 447-454

Jacobson, S. W., \& Frye, K. F. (1991). Effect of a maternal social support on attachment: experimental evidence. Child Development, 62, 572-582.
Johnson, S., Burrows, A., \& Williamson, I. (2004). Does my bump look big in this? The meaning of bodily changes for first-time mothers-to-be. Journal of Health Psychology, 9, 361-374.

Kellam, S. G., \& Horn, Y. V. V. (1997). Life course development, community epidemiology, and preventive trials: a scientific structure for prevention research. American Journal of Community Psychology, 25, 177-188.

Lazarus, R. S., \& Folkman, S. (1984). Stress, appraisal and coping. New York: Springer Publishing Company.

Levandowski, D. C., \& Piccinini, C. A. (2006). Expectativas e sentimentos em relação à paternidade entre adolescentes e adultos. Psicologia: Teoria e Pesquisa, 22, 17-28.

Levandowski, D. C., Piccinini, C. A., \& Lopes, R. C. S. (2009). Individualidade e conjugalidade na relação de casal de adolescentes. Psicologia em Estudo, 14, 679-687.

MacLeod, J., \& Nelson, G. (2000). Programs for the promotion of family wellness and the prevention of child maltreatment: a meta-analytic review. Child Abuse \& Neglect, 24, 1127-1149.

Menezes, C. C., \& Lopes, R. C. S. (2007). Relação conjugal na transição para a parentalidade: gestação até dezoito meses do bebê. PsicoUSF, 12, 83-94.

Mosmann, C. P. (2007). A qualidade conjugal e os estilos educativos parentais. Tese de Doutorado, Universidade Católica do Rio Grande do Sul, Porto Alegre.

Moura, M. L. S., \& Ribas, A. F. P. (2004). Evidências sobre características de bebês recém-nascidos: um convite a reflexões teóricas. In M. L. S. Moura (Ed.), O bebê do século XXI e a psicologia em desenvolvimento (pp. 21-59). São Paulo: Casa do Psicólogo.

Moura, M. L. S., Ribas Jr., R. C., Piccinini, C. A., Bastos, A, C. S., Magalhães, C. M. C., Vieira, M. L., Salomão, N. M. R., Silva, A. M. P. M., \& Silva, A. K. (2004). Conhecimento sobre desenvolvimento infantil em mães primíparas de diferentes centros urbanos do Brasil. Estudos de Psicologia, 9, 421-429.

Murta, S. G. (2007). Programas de prevenção a problemas emocionais e comportamentais em crianças e adolescentes: lições de três décadas de pesquisa. Psicologia: Reflexão e Crítica, 20, 4-11.

Murta, S. G., Rodrigues, A. C, Rosa, I. O., Paulo, S. G., \& Furtado, K. (2008). Grávidos! E agora?! Uma cartilha para pais e mães primíparos. Goiânia: Editora UCG.

Peterson, L., Tremblay, G., Ewigman, B., \& Porkey, C. (2002). The parental daily diary: a sensitive measure of the process of change in a child maltreatment prevention program. Behavior Modification, 26, 627-647.

Piccinini, C. A., Gomes, A. G., Moreira, L. E., \& Lopes, R. S. (2004). Expectativas e sentimentos da gestante em relação ao seu bebê. Psicologia: Teoria e Pesquisa, 20, 223-232.

Piccinini, C. A., Silva, M. R., Gonçalves, T. R., Lopes, R. S., \& Tudge, J. (2004). O envolvimento paterno durante a gestação. Psicologia: Reflexão e Crítica, 17, 303-314.

Posavac, E. J., \& Carey, R. G. (2003). Program evaluation. Methods and case studies. New Jersey: Prentice Hall. $6^{\mathrm{a}}$ ed.

Salvo, C. G., Silvares, E. F. M., \& Toni, P. M. (2005). Práticas educativas como forma de predição de problemas de comportamento e competência social. Estudos de Psicologia, 2, 187-195.

Schwengber, D. D. S., \& Piccinini, C. A. (2004). Depressão materna e interação mãe-bebê no final do primeiro ano de vida. Psicologia: Teoria e Pesquisa, 20, 233-240. 
Shute, J. L., \& Judge, K. (2005). Evaluating "Starting Well", the Scottish national demonstration project for child health: Outcomes at six months. The Journal of Primary Prevention, 26, 221-240.

Silva, A., \& Marturano, E. (2002). Práticas educativas e problemas de comportamento: uma análise a luz das habilidades sociais. Estudos de Psicologia, 7, 227-235.

Silva, N. L. P., \& Dessen, M. A. (2005). Intervenção precoce e família: contribuições do modelo bioecológico de Bronfenbrenner. In M. A. Dessen \& A. L. Costa Júnior (Eds.), A ciência do desenvolvimento humano: tendencias atuais e perspectivas futuras (pp. 152-167). Porto Alegre: Artmed.

Silva, S. S. C., Pendu, Y., Pontes, F. A. R., \& Dubois, M. (2002). Sensibilidade materna durante o banho. Psicologia: Teoria e Pesquisa, 18, 345-353.

Sotto-Mayor, I., \& Piccinini, C. A. (2005). Relacionamento conjugal e depressão materna. Psico, 36, 135-148.

Staudt, A. C. P. (2007). Novos tempos, novos pais? O ser pai na contemporaneidade. Dissertação de Mestrado, Universidade Católica do Rio Grande do Sul, Porto Alegre.
Walsh, F. (2005). Fortalecendo a resiliência familiar (M. F. Lopes, Trad.). São Paulo: Roca (Trabalho original publicado em 1998).

Warren, P. L. (2004). First-time mothers: social support and confidence in infant care. Journal of Advanced Nursing, 50, 479-488.

Wendland-Carro, J., \& Piccinini, C. A (1995). Interação precoce mãe-bebê: perspectivas de intervenção para a promoção do desenvolvimento infantil. Psicologia: Reflexão e Crítica, 8, 111-144.

Wendland-Carro, J., Piccinini, C. A., \& Millar, W. S. (1999). The role of an early intervention on enhancing the quality of motherinfant interaction. Child Development, 70, 713-721.

Recebido em 15.09.2009

Primeira decisão editorial em 16.08.2010

Versão final em 22.09.2010

Aceito em 03.01.2011 